\title{
WT1-Sensitized Allogeneic T-Lymphocytes
}

National Cancer Institute

\section{Source}

National Cancer Institute. WT 1-Sensitized Allogeneic T-Lymphocytes. NCI Thesaurus.

Code C74091.

A population of allogeneic T-cells sensitized with Wilms tumor 1 (WT 1) antigen with potential immunostimulatory and antineoplastic activities. Upon administration, WT1sensitized T cells may bind to and lyse WT 1-expressing tumor cells. WT 1 antigen, a zinc finger DNA-binding protein acting as a transcriptional activator or repressor depending on the cellular or chromosomal context, is overexpressed in leukemic cells and in a vast number of nonhematological solid tumors. 